\title{
Medical treatment, medical research and informed consent
}

\author{
Raanan Gillon Imperial College and King's College, London University
}

One of the themes pursued in Dr Silverman's stimulating paper on 'the myth of informed consent' in this issue (1) is that there is no relevant moral difference between consent to ordinary medical treatment and consent to participation in medical research. It is a theme widely echoed by medical researchers who are often infuriated by the 'paradoxical duality' of standards of consent as Silverman calls them (or in more straightforwardly pejorative terms, the 'double standards', as Chalmers and Baum call them (2)). The common medical researcher's argument goes something like this: ordinary doctors treating their patients are not required to give extensive time-consuming potentially alarming and inadequately comprehended information before giving their treatment - simple patient agreement based on trust suffices. There is no reason why doctors responsibly trying to evaluate the benefits and harms of medical treatments using scientifically approved methods of medical research should be hamstrung by the requirements of so-called 'informed consent'; on the contrary, 'the double standards of ethicists' ... 'must necessarily operate against the interest of patients' (2).

The counter-argument to this type of argument typically goes something like this: doctors generally have no right to do things to patients without their consent and this is equally true of treatment interventions and research interventions. However, in circumstances when the patient's underlying assumption is correct that whatever the doctor proposes to be done will be done in order to try to benefit the patient, and with as little harm as possible, (the normal assumption in the patient-doctor encounter), a patient will often dispense with requests for information about the pros and cons of alternative courses of action and simply trust the doctor to make the best choice for that particular patient. The patient assumes that any important potential problems with the proposed treatment will be pointed out, and it is part of the 'social contract' between patients and doctors that patients' consent to treatment can normally be inferred from the patient's acceptance of a particular medical intervention, though British law has in recent times made clear that patients should be told about 'material' or important risks of proposed treatments and that their questions should be answered truthfully $(3,4,5)$.

However, the counter-argument continues, as soon $\vec{\omega}$ as the 'ground rules' change so that what the doctor 을 proposes is not intended to benefit the patient but $\rightarrow$ becomes part of an enterprise to benefit others, either 3 as well as or even instead of the patient, then it becomes $\frac{\stackrel{m}{*}}{2}$ morally quite unacceptable for the doctor to assume $\stackrel{\rho}{\mathcal{S}}$ the patient's consent to any interventions that might in $\vec{\varphi}$ any way harm or be otherwise unacceptable to the $\stackrel{\circ}{\circ}$ patient; for any such interventions the doctor must $\square$ give the patient explicit information about the pros and cons of the procedures proposed, and seek explicit consent from the patient to use him or her in this way for the benefit of others.

As is usual in moral controversies, there are important moral insights on both sides of this argument, which is considerably more complex than the brief summary given. The insights on the side of treating research comparing two different therapies in the same way as one treats therapy in general include the notion that like ought to be treated as like, that it is $\frac{}{\circ}$ vital to assess our medical interventions so as to ensure 3 . that they are effective and not unexpectedly harmful, $\delta$ and that not all sick patients want to be told in explicit $₹$ detail what precisely is wrong with them and how 0 inadequate current treatment is. The insights on the side of requiring explicit and informed consent to do음 research include the Kantian notion that one must not $\underset{N}{\sim}$ use people merely as means to an end - however $\cong$ worthy the end may be. In order to avoid treating $N$ people merely as means to an end in medical research it $\mathrm{CN}^{N}$ is essential to obtain their deliberated or reasoned 0 consent if they are to be used for the benefit of others. And in order that their consent can be deliberated or reasoned they must have adequate information upon $\stackrel{?}{+}$ which to deliberate or reason.

The latter point is most obvious in the case of

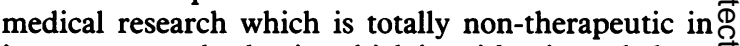
intent - research, that is, which is neither intended nor $\mathbb{\mathbb { Q }}$ expected to provide medical benefit to the subject of $\sigma$ that research. (The further differentiation between non-therapeutic medical research and merely scientifico research on human subjects presumably depends on whether such research is part of the medical enterprise,

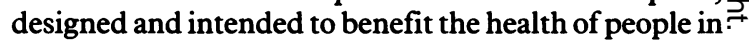


the long run, or whether it is of non-medical scientific value, that is, lacking any intention to benefit people's health, however beneficial or important it may prove to be in other ways).

Healthy volunteer studies are the most obvious examples of non-therapeutic medical research, in which, for example, the effects of medications on normally healthy people are tested. No one has any difficulty in recognising why explicit information and explicit consent from subjects of such research is morally required. A potentially harmful intervention is proposed for the benefit of others' health (for example for the benefit of patients of the future) and there is no intention whatsoever of medically benefiting the subject. Respect for people and their autonomy requires adequately informed consent from the subject before such research can be performed. Arguments, suppose anyone were foolish enough to offer them, that it would be better neither adequately to inform such subjects of proposed non-therapeutic research nor to obtain their explicit consent if such information were likely to be distressing, and that instead the research should be done without giving information or obtaining consent, would be laughed out of court (and into court, if anyone acted upon them).

Is the situation with regard to ordinary medical treatment any different? There seem to be two morally important differences. The first is that the question of being used to benefit others does not arise - ordinary medical treatment simply is not premised on the intention to benefit others. The second and related difference is that there is in the ordinary patient-doctor therapeutic relationship the underlying shared assumption that the doctor will propose any interventions that may risk harm to the patient only if he believes that this will benefit the patient overall (ie that the proposed intervention is likely to produce a net benefit-over-harm for the patient). Given those two assumptions it is reasonable for patients to trust their doctors to act in their interests - and therefore to be far less cautious about scrutinising the interventions they propose than they would normally be if relative strangers proposed to do to them the otherwise extraordinary things that doctors propose to their patients (to mention but a few: the ingestion, injection, apposition or other infliction of strange chemicals; the cutting, burning and sewing of flesh and bone; the destruction or removal of bodily components; the intimate exposure, physical and mental, of private parts; the institutional bedding and infantilising; the unilateral imposition of rules, simple and arcane).

It is because of these two morally relevant differences between non-therapeutic medical research and medical treatment that there is an entirely proper 'double standard' between the moral norms for medical treatment and those required for nontherapeutic medical research. In ordinary medical treatment the doctor does things to the patient in order to benefit the patient. In non-therapeutic medical research the doctor does things to the patient in order to benefit others.

But, opponents of the double standard may argue, clinical research done on patients in the course of their medical management and treatment has nothing to do with non-therapeutic research - such clinical research is all about trying to make sure that doctors are giving their patients the most beneficial and least harmful treatments. Instead of merely observing the results of those treatments - and jumping to often false conclusions - they use the disciplined scientific scrutiny of clinical research, which is of potential benefit both to the patients who are its subjects and to other patients in the future. Such clinical research is morally preferable to mere treatment, unless that treatment has itself been validated by previously conducted clinical research. Thus there should be no moral differences perceived or created between traditional medical treatment, the effects of which should always be under scrutiny for its efficacy and its risks, and the extension of traditional medical treatment known as clinical research, in which the scrutiny of efficacy and risks has been formalised and made more scientifically rigorous than mere clinical observation can ever be. Given this moral assimilation of clinical research to traditional medical treatment no greater requirements of information-giving or of explicit consent are applicable in clinical research than are needed in ordinary medical practice which does not involve research.

Among the problems with any blanket moral assimilation of clinical research to ordinary medical treatment is that there is a spectrum of activities involving medical research on patients, (ie clinical research), at one end of which the research projects are morally similar to ordinary medical treatment and at the other end of which they are morally similar to nontherapeutic medical research. For example if two medications for a particular disease are being compared in a clinical trial and the treating physician has no prior reason to believe that one is better than the other then the research project is from a moral point of view similar to ordinary treatment. (There may of course still arise the moral issue in ordinary treatment whether to consult the patient about his or her preferences between the two treatments - something that is not permitted in principle in a blinded controlled trial - but where such preference might be relevant in ordinary treatment a blinded controlled trial of that treatment immediately shifts the moral balance towards the non-therapeutic end of the spectrum, requiring adequately and explicitly informed consent).

At the other end of the clinical research spectrum, if a patient while being treated for his or her disease is used as a source of clinical material for an unrelated medical research project then the research intervention is from a moral point of view similar to non-therapeutic research. For example, the removal of a kidney or liver biopsy during laparotomy carried out for other reasons, when the biopsy would not otherwise be part 
of the patient's investigation and is neither intended nor anticipated to benefit the patient medically, is an example of clinical research on patients of an entirely non-therapeutic sort. There could be no moral justification for assimilating such research to ordinary medical care for the purpose of moral decision-making or analysis, though of course it would still be perfectly accurate to call it clinical research. Such research would be properly classified as non-therapeutic clinical research under the terms of the Helsinki Declaration (6).

Much clinical research on patients involving the assessment of therapies and potential therapies is not unequivocally at one end or the other of this therapeutic/non-therapeutic spectrum, but in between. To the extent that there is prior reason (though not yet scientifically validated reason) to believe that the intervention under investigation will benefit the patient more than current best available treatments - or harm the patient less - the intervention is at the ordinary medical treatment or therapeutic end of the moral spectrum. To the extent that such prior reasonable belief is unjustified the intervention is at the non-therapeutic end of the moral spectrum.

There is nothing intrinsically wrong with nontherapeutic research on patients, nor with clinical research which is both therapeutic and nontherapeutic in intent (ie is intended both to benefit the patient and to benefit other patients in the future). On the contrary, the development of new treatments for patients of the future is an admirable objective and it is admirable if patients participate as subjects in such research. But doctors have no more right to assume the consent of their patients to participate in research designed to benefit others than any other do-gooder (doer of good) has to assume the consent of those others whom he wishes to enroll in his admirable activities. We would be shocked if someone gaining entry to an old lady's house on the grounds of doing her good meals on wheels or cleaning her floors or whatever then helped himself to the odd coin he found lying around - even if he immediately popped it into his collecting tin for cancer research, and even if he did a very good job of cleaning the house or serving the meal. The more our normal, index-patient-orientated, treatment becomes mixed with research activities designed to benefit others the more like that sort of dogooder we become - unless we are punctilious about explaining precisely to the subjects of our research what we would like to do and why, and punctilious in obtaining their adequately informed consent (permission) to do it.

The surgeon who, while doing a laparotomy snitches a bit of liver for an unrelated research project, or the medical researcher who takes a little extra blood for an unrelated medical research project, are both behaving analogously to the do-gooder who takes the coin without permission. So too are any other medical researchers who assume their patients' consent to additional research interventions designed for the benefit of others simply because they are at the same $\stackrel{\Pi}{\overrightarrow{5}}$. time giving those patients medical treatment that is intended to benefit them.

There seems to be a simple rule of thumb for $\stackrel{\overrightarrow{\vec{D}}}{\rightarrow}$ distinguishing between therapeutic and non- $\bar{C}$ therapeutic clinical research: would I, the researching $\underline{\bar{E}}$ doctor, normally have good reason to subject my $\frac{\bar{\sigma}}{\overrightarrow{0}}$

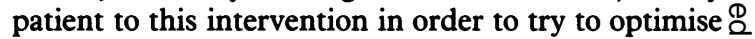
his or her medical management and treatment? If the answer is yes, then the research project is therapeutic $\vec{A}$

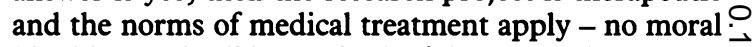
'double standard' is required. If the answer is no, then $\vec{\omega}$ some element of non-therapeutic intervention is likely to be involved and the standards of non-therapeutic research designed to benefit others are likely to become $\stackrel{\Phi}{\top}$ relevant, rather than those of ordinary treatment. The $\vec{T}$ less the research interventions are designed to benefit $\vec{\omega}$ the subject-patients the more those explicit standards 0 of non-therapeutic research become mandatory, and $\triangle$ the less justified are we in expecting or allowing our $z$ patients to acquiesce in our clinical research without adequate and explicit information and consent.

In summary then, both sides of the debate can be $\vec{\varphi}$ seen to be partly right. There is indeed no justification ${ }_{0}^{\circ}$ for a double moral standard for those activities which are morally equivalent. Some sorts of clinical research? are morally equivalent to well-observed medical treatment, and should be subject to the same moral norms as well-observed medical treatment. However, $\frac{\circ}{\circ}$ not all research on patients (ie clinical research) does $\stackrel{\varrho}{\rightarrow}$ fall into the same moral category as medical treatment. $\overrightarrow{0}$ Some is clearly in the category of non-therapeutic medical research and a moral 'double standard' is not just acceptable but imperative, for it would be trading on false pretences either to allow patients to believe that such research is being carried out on them in order $\frac{\Phi}{-}$ to benefit them - or simply not tell them it is 3 . happening. Much clinical research falls between the two polar positions. The nearer it is to one end of the 3 spectrum the more it should be treated as such from a 0 moral point of view. Only research that is at or near the therapeutic pole of the spectrum can properly assume $\rightarrow$ the implied consent that is so often a normal and proper part of the ordinary doctor-patient relationship. $N$ Doctors involved in clinical research surely need to be N very clear about the moral differences between therapeutic and non-therapeutic clinical research, and ${ }_{\sigma}^{\omega}$ the morally appropriate 'double standards' that should be applied to them. For any new clinical research $\stackrel{0}{\circ}$ project they need to try to decide how far towards one or other pole on the spectrum the project lies and act ${ }_{7}$ accordingly. Those who refuse to acknowledge the moral distinction between therapeutic and non- $\overrightarrow{\mathbb{D}}$ therapeutic clinical research are likely to bring about $\stackrel{?}{\mathbb{P}}$ the very deterioration in patients' trust of their doctors $\cong$ which they may be inclined to bemoan.

\section{References}

(1) Silverman W A. The myth of informed consent: in dailyo

(Continued on page 11) 
(22) Herbst A L, Ulfeder H, Poskanzer D C. Adenocarcinoma of the vagina: association of maternal stilbestrol with tumour appearance in young women. New England journal of medicine $1971 ; 284: 878-881$.

(23) Heinonen O P. Diethylstilbestrol in pregnancy. Cancer $1973 ; 31: 573-577$.

(24) National Commission for the Protection of Human Subjects of Biomedical and Behavioural Research.
Research involving children: report and recommendation. Document No (OS) 77-0004 Washington: Government Printing Office, 1977.

(25) Kauffman C L. Informed consent and patient decision making: two decades of research. Social science and medicine 1983; 17:1657-1664.

(26) Edlund $M$ J, Craig T J, Richardson M A. Informed consent as a form of volunteer bias. American journal of psychiatry 1985; 142:624-627.

\section{(Continued from page 5)}

practice and in clinical trials. Fournal of medical ethics $1989 ; 15: 6-11$.

(2) Chalmers I, Baum M. Consent to randomised treatment [letter]. Lancet 1982; ii:1051.

(3) Mason J K, McCall Smith R A. Law and medical ethics (2nd ed). London: Butterworths, 1987: 152-159.
(4) Sidaway v Board of Governors of the Bethlem Royal Hospital; [1985] 1 All ER 643, HL.

(5) Anonymous. Adequately informed consent [editorial] fournal of medical ethics 1985; 11:115-116.

(6) Declaration of Helsinki. In: British Medical Association The handbook of medical ethics. London: BMA Publications, 1984: 73-76. 